\title{
Relationship between cyclooxygenase $8473 T>C$ polymorphism and the risk of lung cancer: a case-control study
} Jung Min Park ${ }^{1}$, Jin Eun Choi ${ }^{1}$, Myung Hwa Chae ${ }^{1}$, Won Kee Lee ${ }^{2}$, Sung Ick Cha ${ }^{3}$, Ji-Woong Son ${ }^{4}$, Chang Ho Kim³ ${ }^{3}$ Sin Kam², Young Mo Kang ${ }^{3}$, Tae Hoon Jung ${ }^{3}$ and Jae Yong Park*1,3

\begin{abstract}
Address: ${ }^{1}$ Cancer Research Institute, School of Medicine, Kyungpook National University, Dong In 2Ga 101, Daegu, 700-422, South Korea, ${ }^{2}$ Department of Preventive Medicine, School of Medicine, Kyungpook National University, Dong In 2Ga 101, Daegu, 700-422, South Korea, ${ }^{3}$ Department of Internal Medicine, School of Medicine, Kyungpook National University, Dong In 2Ga 101, Daegu, 700-422, South Korea and ${ }^{4}$ Department of Internal Medicine, Konyang University College of Medicine, Naedong 26, Nonsan, 320-711, Korea

Email: Jung Min Park - qhrhtgsy@hanmail.net; Jin Eun Choi - ddochi74@hanmail.net; Myung Hwa Chae - mhchae@hanmail.net; Won Kee Lee -wonlee@knu.ac.kr; Sung Ick Cha - sicha@knu.ac.kr; Ji-Woong Son - sk1609@hanmail.net; Chang Ho Kim - kimch@knu.ac.kr; Sin Kam - kamshin@knu.ac.kr; Young Mo Kang - ymkang@knu.ac.kr; Tae Hoon Jung - thjung@knu.ac.kr; Jae Yong Park* - jaeyong@knu.ac.kr

* Corresponding author
\end{abstract}

Published: 17 March 2006

BMC Cancer 2006, 6:70 doi:10.1 186/147/-2407-6-70
Received: 21 November 2005

Accepted: 17 March 2006

This article is available from: http://www.biomedcentral.com/I47I-2407/6/70

(c) 2006 Park et al; licensee BioMed Central Ltd.

This is an Open Access article distributed under the terms of the Creative Commons Attribution License (http://creativecommons.org/licenses/by/2.0), which permits unrestricted use, distribution, and reproduction in any medium, provided the original work is properly cited.

\begin{abstract}
Background: Cyclooxygenase-2 (COX-2) plays an important role in the development of lung cancer. DNA sequence variations in the COX-2 gene may lead to altered COX-2 production and/ or activity, and so they cause inter-individual differences in the susceptibility to lung cancer. To test this hypothesis, we investigated the association between the $8473 T>C$ polymorphism in the 3'untranslated region of the COX-2 gene and the risk of lung cancer in a Korean population.
\end{abstract}

Methods: The COX-2 genotypes were determined using PCR-based primer-introduced restriction analysis in 582 lung cancer patients and in $\mathbf{5 8 2}$ healthy controls that were frequency-matched for age and gender.

Results: The distribution of the COX-2 8473T $>$ C genotypes was not significantly different between the overall lung cancer cases and the controls. However, when the cases were categorized by the tumor histology, the combined 8473 TC + CC genotype was associated with a significantly decreased risk of adenocarcinoma as compared with the 8473 TT genotype (adjusted OR $=0.64$; $95 \% \mathrm{Cl}=0.46-0.90, P=0.0 \mathrm{I})$. On the stratification analysis, the protective effect of the combined 8473 TC + CC genotype against adenocarcinoma was statistically significant in the males, older individuals and ever-smokers (adjusted $\mathrm{OR}=0.59 ; 95 \% \mathrm{Cl}=0.39-0.91, P=0.02$; adjusted $\mathrm{OR}=$ $0.55 ; 95 \% \mathrm{Cl}=0.33-0.93, P=0.03$; and adjusted $\mathrm{OR}=0.57 ; 95 \% \mathrm{Cl}=0.37-0.87, P=0.01$, respectively).

Conclusion: These findings suggest that the COX-2 $8473 T>C$ polymorphism could be used as a marker for the genetic susceptibility to adenocarcinoma of the lung. 


\section{Background}

Although cigarette smoking is the major cause of lung cancer, only a fraction of smokers develop lung cancer during their lifetime, and this suggests that genetic factors are of importance in determining an individual's susceptibility to lung cancer [1].

Cyclooxygenase (COX, also known as prostanglandin endoperoxide synthase) is the rate-limiting enzyme for the production of prostaglandins (PGs) from free arachidonic acid. Two isoforms of COX have been identified. COX-1 is constitutively expressed in most normal tissues and it is considered to be a housekeeping enzyme that is responsible for various physiologic functions. In contrast, COX-2 is rarely expressed in normal tissues, but it is rapidly induced in response to cytokines, growth factors and tumor promoters [2. 3]. Overexpression of COX-2 has been reported in a variety of human malignancies, including lung cancer [4-6]. Up-regulation of COX-2 can promote tumor growth and metastasis by stimulating cell proliferation, angiogenesis, and invasiveness in addition to inhibiting apoptosis and immune surveillance [7-10]. Moreover, a number of epidemiologic studies have recently suggested that COX-2 inhibitor may have a protective effect on the development of lung cancer $[11,12]$. Taken together, these observations indicate that COX-2 plays an important role in the development of lung cancer. In addition, several studies have shown that the frequency and level of COX-2 up-regulation was higher in adenocarcinoma (AC) than in squamous cell carcinoma (SCC), and small cell carcinoma (SM) showed virtually negligible expression $[6,13,14]$. This suggests that the COX-2 gene may have a pronounced association with the development of AC.

Single nucleotide polymorphisms are the most common form of human genetic variation, and they may contribute to the individual susceptibility to cancer. Many studies have demonstrated that some of these variants affect either the expression or activities of enzymes; therefore, they are associated with the risk of cancer $[15,16]$. Thus, we hypothesized that functional SNPs in the COX-2 gene may have an impact on COX-2 expression or activity, and so they modulate the susceptibility to lung cancer. To test this hypothesis, a case-control study was conducted to evaluate the association between COX-2 polymorphisms and the risk of lung cancer. Among the identified COX-2 polymorphisms [17-19], we have focused on the $1186 T>G$ and $-765 G>C$ in the promoter region and the $8473 T>C$ in the 3 '-untranslated region (3'-UTR) since these polymorphisms in the transcription or posttranscriptional regulatory regions have been reported to be associated with various human diseases [17-21]. In the present study, we evaluated with the association of the 8473T>C polymorphism with lung cancer because the -
1186T>G and $-765 G>C$ polymorphisms were not detected in a preliminary study that consisted of 27 lung cancer cases and 27 healthy controls.

\section{Methods \\ Study population}

This case-control study included 582 lung cancer patients and 582 healthy controls. The details of the study population have been described elsewhere [22-24]. In brief, the eligible cases included all the patients who were newly diagnosed with primary lung cancer between January 2001 and June 2002 at Kyungpook National University Hospital, Daegu, Korea. There were no age, gender, histological or stage restrictions, but patients with a prior history of cancers were excluded from this study. The cases included 270 (46.4\%) SCCs, 205 (35.2\%) ACs, 97 $(16.7 \%)$ SMs, and $10(1.7 \%)$ large cell carcinomas. The demographics and clinical characteristics of the cases were consistent with those of a nationwide lung cancer survey conducted by the Korean Academy of Tuberculosis and Respiratory Disease in 1998 [25]. The control subjects were randomly selected from a pool of healthy volunteers who visited the general health check-up center at Kyungpook National University Hospital during the same period. The control subjects were frequency matched $(1: 1)$ to the cancer cases based on gender and age $( \pm 5$ years). All the cases and the controls were ethnic Koreans and they resided in Daegu City or the surrounding regions. A detailed questionnaire was completed for each patient and control by a trained interviewer. The questionnaire included information on the average number of cigarettes smoked daily and the number of years the subjects had been smoking. For smoking status, a person who had smoked at least once a day for $>1$ year in his or her lifetime was regarded as a smoker. A former smoker was defined as one who had stopped smoking at least 1 year before diagnosis in the case of patients and 1 year before the date signed on an informed consent for blood sample collection in the case of controls. Cumulative cigarette dose (pack-years) was calculated using the following formula: pack-years $=($ packs per day $) \times($ years smoked $)$. This study was approved by the institutional review board of the Kyungpook National University Hospital, and written informed consent was obtained from each participant.

\section{COX-2 genotyping}

Genomic DNA was extracted from peripheral blood lymphocytes by proteinase $\mathrm{K}$ digestion and phenol/chloroform extraction. The COX-2 8473T>C genotype was determined using PCR-based primer-introduced restriction analysis (PIRA) as described by Hu et al. [26]. The PCR products were digested overnight with 10 units of BclI (New England BioLabs, Inc., Beverly, MA, USA) at $50^{\circ} \mathrm{C}$. The digested PCR products were resolved on $6 \%$ acrylamide gel and stained with ethidium bromide for vis- 
ualization under UV light. To ensure quality control, the genotyping analysis was performed "blind" with respect to case/control status. About $10 \%$ of the samples were randomly selected to be genotyped again by a different author, and the results were $100 \%$ concordant. To confirm the genotyping results, selected PCR-amplified DNA samples ( $\mathrm{n}=2$, respectively, for each genotype) were examined by DNA sequencing, and the results were also $100 \%$ concordant.

\section{Statistical analysis}

Cases and controls were compared using the Student's ttest for continuous variables and the $\chi^{2}$ test for categorical variables. Hardy-Weinberg equilibrium was tested with a goodness-of-fit $\chi^{2}$ test with one degree of freedom for the comparing the observed genotype frequencies with the expected genotype frequencies among the subjects. Unconditional logistic regression analysis was used to calculate odds ratios (ORs) and 95\% confidence intervals (CIs), with adjustment for the possible confounders (gender as a nominal variable; age and pack-years of smoking, as continuous variables). Multivariate logistic regression analyses were performed to analyze the association between the genotypes and the risk of lung cancer after stratification according to age (median age), gender, smoking status, cigarette consumption (median packyears), and histological types of lung cancer. In case of subgroup analysis for AC, the smoking status was categorized into two groups: never-smokers and ever-smokers (former- and current-smokers) since the number of former smokers in the AC cases was small $(n=29)$. All analyses were performed using Statistical Analysis Software for Windows, version 8.12 (SAS institute, Gary, NC, USA).

\section{Results}

The demographics of the cases and controls enrolled in this study are shown in Table 1 . There were no significant differences between the cases and controls for the mean age or gender distribution, and this suggested that the matching based on these two variables was adequate. The case group had a higher prevalence of current smokers than did the controls $(P<0.001)$, and the number of pack-years in the smokers was significantly higher in the cases than in the controls $(40.0 \pm 17.7$ versus $34.1 \pm 17.8$ pack-years; $P<0.001)$. These differences were controlled in the later multivariate analyses.

The genotypes and polymorphic $8473 \mathrm{C}$ allele frequencies of the COX-2 8473T>C polymorphism among the controls and cases are shown in Table 2. The distribution of the genotypes among the controls was in Hardy-Weinberg equilibrium $(\chi=0.35, P=0.55)$. No significant deviation was observed for the distribution of the genotypes between the overall lung cancer cases and the controls.
Table I: Characteristics of the study population

\begin{tabular}{lcl}
\hline Variable & Cases $(\mathrm{n}=582)$ & Controls $(\mathrm{n}=582)$ \\
\hline $\begin{array}{l}\text { Age (years) } \\
\text { Sex }\end{array}$ & $61.3 \pm 9.4$ & $60.2 \pm 9.6$ \\
$\quad$ Male & $467(80.2)^{\mathrm{a}}$ & $467(80.2)$ \\
$\quad \begin{array}{l}\text { Female } \\
\text { Smoking status }\end{array}$ & $115(19.8)$ & $115(19.8)$ \\
$\quad$ Current & $387(66.5)$ & $297(51.0)$ \\
$\quad$ Former & $85(14.6)$ & $147(25.3)$ \\
$\quad$ Never & $110(18.9)$ & $138(23.7)$ \\
Pack-yearsc & $40.0 \pm 17.7$ & $34.1 \pm 17.8$ \\
\hline
\end{tabular}

aNumbers in parenthesis, percentage.

bP $<0.001$.

cIn current and former smokers, $P<0.001$.

However, when the cases were categorized by the tumor histology, the distribution of the $8473 T>C$ genotypes among the AC cases differed significantly from that among the controls $(P=0.04)$. The distributions of the genotypes in the SCC and SM groups were not significantly different from that among the controls.

The lung cancer risk related to the COX-2 8473T>C genotypes was also shown in Table 2. When the 8473 TT genotype was used as the reference group, the $8473 \mathrm{TC}$ and the 8473 CC genotypes were associated with a non-significant decreased risk for overall lung cancer, respectively [adjusted odds ratio $(\mathrm{OR})=0.87 ; 95 \%$ confidence interval $(\mathrm{CI})=0.68-1.11$; and adjusted $\mathrm{OR}=0.72 ; 95 \% \mathrm{CI}=0.41-$ 1.25 , respectively). When the analyses were stratified by the tumor histology, the 8473 TC genotype and the combined $8473 T C+C C$ genotype were associated with a significantly decreased risk of $\mathrm{AC}$, respectively (adjusted OR $=0.64 ; 95 \% \mathrm{CI}=0.45-0.91, P=0.01$; and adjusted $\mathrm{OR}=$ $0.64 ; 95 \% \mathrm{CI}=0.46-0.90, P=0.01$, respectively). No significant association was found between the $8473 T>C$ polymorphism and the risk of SCC or SM.

The association between the COX-2 8473T>C genotypes and the risk of $\mathrm{AC}$ was further examined by stratifying according to gender, age and the smoking status (Table 3 ). As compared with the 8473 TT genotype, the combined $8473 T C+C C$ genotype was associated with a significantly decreased risk of $\mathrm{AC}$ in the males and older individuals (adjusted OR $=0.59 ; 95 \% \mathrm{CI}=0.39-0.91, P=0.02$; and adjusted $\mathrm{OR}=0.55 ; 95 \% \mathrm{CI}=0.33-0.93, P=0.03$, respectively), whereas it had no significant effect of the risk of $\mathrm{AC}$ in the females and younger individuals. When stratified by the smoking status, a significant protective effect of the combined $8473 \mathrm{TC}+\mathrm{CC}$ genotype against AC was observed in the ever-smokers (adjusted OR $=0.57 ; 95 \%$ $\mathrm{CI}=0.37-0.87, P=0.01$ ), but not in never-smokers. When the ever-smokers were dichotomized by the median 
Table 2: Distribution of COX-2 8473T>C genotype in controls and cases

\begin{tabular}{|c|c|c|c|c|c|c|}
\hline \multirow[t]{2}{*}{ Genotype } & \multirow{2}{*}{$\begin{array}{c}\text { Control } \\
\text { no. }\end{array}$} & \multirow{2}{*}{$\begin{array}{c}\text { Case no. } \\
(\mathrm{SQ} / \mathrm{AD} / \mathrm{LA} / \mathrm{SM})^{\mathrm{a}}\end{array}$} & \multicolumn{4}{|c|}{ Crude OR $(95 \% \mathrm{Cl}) /$ Adjustedb OR $(95 \% \mathrm{Cl})$} \\
\hline & & & All Cases & $\mathrm{SQ}^{\mathrm{a}}$ & $A D^{a}$ & SMa \\
\hline$T T$ & 330 & $352(152 / 137 / 4 / 59)$ & 1.0 & 1.0 & 1.0 & 1.0 \\
\hline TC & 220 & $205(108 / 60 / 6 / 31)$ & $\begin{array}{l}0.87(0.69-1.11) / \\
0.87(0.68-1.11)\end{array}$ & $\begin{array}{l}1.07(0.79-1.44) / \\
1.06(0.78-1.45)\end{array}$ & $\begin{array}{l}0.66(0.46-0.93)^{c /} \\
0.64(0.45-0.91)^{d}\end{array}$ & $\begin{array}{l}1.22(0.52-2.90) / \\
1.13(0.47-2.74)\end{array}$ \\
\hline CC & 32 & $25(10 / 8 / 0 / 7)$ & $\begin{array}{l}0.73(0.43-1.26) / \\
0.7 I(0.4 I-1.23)\end{array}$ & $\begin{array}{l}0.68(0.33-1.42) / \\
0.66(0.31-1.42)\end{array}$ & $\begin{array}{l}0.60(0.27-1.34) / \\
0.67(0.29-1.50)\end{array}$ & $\begin{array}{l}0.79(0.49-1.26) / \\
0.78(0.48-1.26)\end{array}$ \\
\hline$T C+C C$ & 252 & $230(118 / 68 / 6 / 38)$ & $\begin{array}{l}0.86(0.68-1.08) / \\
0.85(0.67-1.07)\end{array}$ & $\begin{array}{l}1.02(0.76-1.36) / \\
1.01(0.75-1.37)\end{array}$ & $\begin{array}{l}0.65(0.47-0.91)^{d} / \\
0.64(0.46-0.90)^{d}\end{array}$ & $\begin{array}{l}0.84(0.54-1.31) / \\
0.83(0.53-1.30)\end{array}$ \\
\hline Age & & & - & $1.01(0.99-1.03)$ & $0.98(0.97-1.00)$ & $1.03(1.00-1.05)^{\mathrm{e}}$ \\
\hline Gender (male: 0 , female: I) & & & - & $0.97(0.55-1.69)$ & $3.33(2.09-5.32)^{f}$ & $1.01(0.46-2.26)$ \\
\hline Pack-years of smoking & & & $1.01(1 . \overline{0} 1-1.02)^{f}$ & $1.03(1.02-1.04)^{f}$ & $1.01(1.00-1.02)$ & $1.02(1.01-1.03)^{f}$ \\
\hline
\end{tabular}

aSQ, squamous cell ca.; AD, adenoca.; LA, large cell ca.; and SM, small cell ca.

bAdjusted for pack-years for all cases; and adjusted for age, gender and pack-years for SQ, AD and SM.

$c P=0.02$.

$\mathrm{d} P=0.01$.

$\mathrm{e} P=0.04$.

$f P<0.001$.

pack-years of smoking, the protective effect of the combined $8473 T C+C C$ genotype was similar in lighter smokers and heavier smokers (data not shown).

\section{Discussion}

We investigated the influence of COX-2 polymorphisms on the risk of lung cancer by conducting a hospital-based case-control study. The $8473 T>C$ polymorphism in the $3^{\prime}-$ UTR region of the COX-2 gene was associated with a significantly decreased risk of $\mathrm{AC}$ of the lung. The protective effects were evident in the males, the older individuals and the smokers. These findings suggest that the COX-2 $8473 T>C$ polymorphism could be used as a marker for the genetic susceptibility to $\mathrm{AC}$ of the lung. Of three major histological types of lung cancer, the proportion of $\mathrm{AC}$ is increasing world-wide. Thus, identifying the genetic factors that are responsible for the susceptibility to AC is indispensable for establishing novel and efficient ways to prevent this disease.

Because the COX-2 $-1186 T>G$ and $-765 G>C$ polymorphisms were not detected in the preliminary study that included 27 healthy controls and 27 lung cancer cases, we analyzed only the association of the COX-2 8473T>C polymorphism with the risk of lung cancer. The frequency of the COX-2 $8473 \mathrm{C}$ allele among the healthy controls in the current study was 0.244 , which was significantly lower than that (0.535) of healthy Norwegians [18], but it was significantly higher than that $(0.187)$ of healthy Chinese [26].
In the current study, the COX-2 8473T>C polymorphism was significantly associated with the risk of $\mathrm{AC}$, but it was not associated with SCC or SM. Although the reasons for the observed histology-specific difference in the risk conferred by the COX-2 polymorphism remain to be elucidated, this difference may be attributable to the differences in the pathways of carcinogenesis among the different histological types of lung cancer. Therefore, certain genotypes could confer a greater susceptibility to a particular histological type of lung cancer $[22-24,27,28]$. Several studies have shown that the frequency and level of COX-2 up-regulation was higher in the ACs than in the SCCs, and the SMs showed a virtually negligible expression $[6,13,14]$. These observations suggest that the COX-2 gene may have a pronounced association with the development of $\mathrm{AC}$, and they are comparable with our finding that the COX-2 polymorphism plays an important role in determining the genetic susceptibility to AC.

A few studies have investigated the association between the COX-2 8473T>C polymorphism and the risk of lung cancer $[18,26]$. Campa et al. [18] have reported that the $8473 \mathrm{TC}$ and the $8473 \mathrm{CC}$ genotypes were associated with a significantly increased risk of lung cancer in a Norwegian population. In contrast to the Norwegian study, $\mathrm{Hu}$ et al. [26] have reported that the combined $8473 \mathrm{TC}+\mathrm{CC}$ genotype was associated with a significantly decreased risk of lung cancer in a Chinese population. In concordance with the Chinese study, the combined 8473 TC + CC genotype was associated with a significantly decreased risk of AC in our current study. Although it is hard to decipher the reasons for the oppositely directed association of the 
Table 3: Analysis of COX-2 8473T $>C$ genotype frequencies, ORs and $95 \%$ Cls for adenocarcinoma by selected variables

\begin{tabular}{|c|c|c|c|c|c|c|c|c|}
\hline \multirow[t]{3}{*}{ Variable } & \multicolumn{6}{|c|}{ Genotype, no (\%) } & & \\
\hline & \multicolumn{3}{|c|}{ Cases } & \multicolumn{3}{|c|}{ Controls } & \multicolumn{2}{|c|}{ OR $(95 \% \mathrm{Cl})$ for $T C+C C$ vs $T T$} \\
\hline & $T T$ & $T C$ & $C C$ & $T T$ & $T C$ & CC & Crude & Adjusted \\
\hline \multicolumn{9}{|l|}{ Gender } \\
\hline Male & $86(68.2)$ & $35(27.8)$ & $5(4.0)$ & $265(56.8)$ & 175 (37.5) & $27(5.8)$ & $0.6 \mathrm{I}(0.40-0.93)^{\mathrm{a}}$ & $0.59(0.39-0.91)^{\mathrm{a}, \mathrm{b}}$ \\
\hline Female & $51(64.6)$ & $25(31.7)$ & $3(3.8)$ & $65(56.5)$ & $45(39.1)$ & $5(4.4)$ & $0.7 \mid(0.40-1.29)$ & $0.72(0.40-1.30)^{\mathrm{b}}$ \\
\hline \multicolumn{9}{|l|}{ Age (years) } \\
\hline$\leq 60$ & $69(62.7)$ & $39(35.5)$ & $2(1.8)$ & I $58(55.1)$ & $115(40.1)$ & 14 (4.9) & $0.73(0.46-1.14)$ & $0.74(0.47-1.16)^{c}$ \\
\hline$>60$ & $68(71.6)$ & $21(22.1)$ & $6(6.3)$ & $172(58.3)$ & $105(35.6)$ & $18(6.1)$ & $0.56(0.34-0.92)^{\mathrm{a}}$ & $0.55(0.33-0.93)^{c, d}$ \\
\hline \multicolumn{9}{|c|}{ Smoking status } \\
\hline Never & $49(61.2)$ & $28(35.0)$ & $3(3.8)$ & $77(55.8)$ & $53(38.4)$ & $8(5.8)$ & $0.80(0.46-1.40)$ & $0.77(0.43-1.36)^{c}$ \\
\hline Everf & $88(70.4)$ & $32(25.6)$ & $5(4.0)$ & $253(57.0)$ & $167(37.6)$ & $24(5.4)$ & $0.56(0.36-0.85)^{g}$ & $0.57(0.37-0.87)^{\mathrm{e}, \mathrm{g}}$ \\
\hline \multicolumn{9}{|c|}{ Pack-years in ever-smokers ${ }^{f}$} \\
\hline$\leq 35$ pys & $46(74.2)$ & $14(22.6)$ & $2(3.2)$ & | 47 (59.0) & $89(35.7)$ & $13(5.2)$ & $0.50(0.27-0.93)^{\mathrm{d}}$ & $0.5 \mathrm{I}(0.27-0.96)^{\mathrm{e}, \mathrm{h}}$ \\
\hline$>35$ pys & $42(66.7)$ & $18(28.6)$ & $3(4.8)$ & $106(54.4)$ & $78(40.0)$ & II (5.6) & $0.60(0.33-1.08)$ & $0.60(0.33-1.10)^{\mathrm{e}}$ \\
\hline
\end{tabular}

$\mathrm{aP}=0.02$.

bAdjusted for age and pack-years of smoking.

cAdjusted for gender and pack-years of smoking.

$\mathrm{d} P=0.03$.

eAdjusted for gender and age.

fFormer- and current-smokers.

$g P=0.01$.

$\mathrm{hP}=0.04$.

COX-2 8473T>C polymorphism for lung cancer in the different studies, several genetic and environmental factors that are relevant to this polymorphism might have caused the different results. Moreover, since a protective genotype in one population may increase the cancer risk in another population due to other linked polymorphisms that exhibit stronger effects on the susceptibility to cancer, the different genetic background of the study subjects should be also considered. In addition, inadequate study design such as nonrandom sampling, a limited sample size and the pitfalls arising from unknown confounders should be also considered.

Whether the COX-2 8473T>C polymorphism itself alters mRNA stability and/or translation efficiency or if it is in linkage disequilibrium with the other functional polymorphisms remains to be investigated. The 3'-UTR region of COX-2 contains highly conserved adenosine- and uridine-rich elements that are composed of the Shaw-Kamens sequence (AUUUA), which is also known as AU rich elements [29]. This motif is present within the 3'-UTRs of many protooncogenes and cytokine genes, and it is involved in the regulation of COX-2 production by acting both as a message instability determinant and a translation inhibitory element [30-32]. Therefore, the 8473T>C polymorphism located within the functional region of 3'UTR of the COX-2 gene may affect the message stability and/or translation efficiency, and so this results in differential COX-2 expression.

Several polymorphisms have been identified in the promoter region of the COX-2 gene [17-19]. The -765G>C polymorphism, which is located at just $5^{\prime}$ to a STAT1 binding site, has been found to influence COX-2 expression and it contributes to the risk of various human diseases $[17,21,33]$. Although the frequency of carrying the 765 GC or CC genotype has been reported to be $25 \%$ to $50 \%$ in Caucasians $[17,21,33]$, the $-765 G>C$ polymorphism was not detected in the preliminary study that included 27 healthy controls. These samples included 54 chromosomes, and this provides for at least a $95 \%$ confident level to detect alleles with frequencies of $>5 \%$. Thus, it is very likely that if this polymorphism exists, it may not play a major role in the genetic susceptibility to lung cancer in the Korean population [34,35]. Kang et al. [19] have recently reported that the $-1186 T>G$ polymorphism in the nuclear factor kappa-B binding region was associated with the risk of bladder cancer in a Korean population. In this study, however, the $-1186 T>G$ polymorphism was very rare (the frequency of the $-1186 \mathrm{G}$ allele was $1.0 \%$ ), and this not associated with the risk of lung cancer. In the current study, the $-1186 T>G$ polymorphism was not detected in the preliminary study that included 27 healthy controls and 27 lung cancer cases, suggesting that this polymor- 
phism may not play a major role in the genetic susceptibility to lung cancer in the Korean population.

During multistage carcinogenesis, COX-2 can enhance tumor invasion and metastasis [7-10]; therefore, the COX$28473 T>C$ polymorphism may have an influence on the progression of disease. In the present study, however, no significant difference was observed in the genotype distribution according to the stage of lung cancer (data not shown).

\section{Conclusion}

We found that the 8473T>C polymorphism in the 3 '-UTR region of the COX-2 gene was associated with the risk of lung cancer, and particularly for the risk of AC. This result indicates that this polymorphism could be used as one marker for defining the risk of lung cancer. However, it is possible that our findings, particularly those findings from stratified analyses, can be attributed to chance because of multiple comparisons and/or the relatively small numbers of subjects in the subgroups. Therefore, additional studies with larger sample sizes will be required to confirm these findings. Future studies on the other COX-2 sequence variants and their biologic function are also needed to understand the role of the COX-2 polymorphisms in determining the risk of lung cancer. Moreover, since genetic polymorphisms often vary significantly between the different ethnic groups, further studies are warranted to clarify the association of the COX-2 polymorphisms with the risk of lung cancer in diverse ethnic populations.

\section{Competing interests}

The author(s) declare that they have no competing interests.

\section{Authors' contributions}

JMP, JEC and MHC carried out a PCR-RFLP assay and participated in interpretation of data. WKL and SK participated in the design of study, and analysis and interpretation of data. SIC, JWS and CHK collected clinical data and helped to draft the manuscript. YMK and THJ participated in the design of study, acquisition of data and interpretation of data. JYP conceived the study and participated in the design of study, analysis and interpretation of data, drafting the article and final approval of this version. All authors read and approved the final manuscript.

\section{Acknowledgements}

This study was supported by a Grant No. RTI04-0I-0I, The Regional Technology Innovation Program of The Ministry of Commerce, Industry and Energy (MOCIE).

\section{References}

I. Shields PG, Harris CC: Cancer risk and low-penetrance susceptibility genes in gene-environment interactions. J Clin Oncol 2000, I 8( I I ):2309-23 I5.

2. Dubois RN, Abramson SB, Crofford L, Gupta RA, Simon LS, Van De Putte LB, Lipsky PE: Cyclooxygenases in biology and disease. FASEB J 1998, I 2(12): I063-1073.

3. Smith WL, DeWitt DL, Garavito RM: Cyclooxygenases: structural, cellular, and molecular biology. Annu Rev Biochem 2000, 69:145-182.

4. Eberhart CE, Coffey RJ, Radhika A, Giardiello FM, Ferrenbach S, Dubois RN: Up-regulation of cyclooxygenase 2 gene expression in human colorectal adenomas and adenocarcinomas. Gastroenterology 1994, I 07(4): I I83- I I88.

5. Parrett ML, Harris RE, Joarder FS, Ross MS, Clausen KP, Robertson FM: Cyclooxygenase-2 expression in human breast cancer. Int J Oncol 1997, 10:503-507.

6. Wolff H, Saukkonen K, Anttila S, Karjalainen A, Vainio H, Ristimaki A: Expression of Cyclooxygenase-2 in human lung carcinoma. Cancer Res 1998, 58(22):4997-500I.

7. Sheng H, Shao J, Washington MK, DuBois RN: Prostaglandin E2 increases growth and motility of colorectal carcinoma cells. J Biol Chem 200I, 276(2I): I8075-I808I.

8. Tsujii M, Kawano S, Tsujii S, Sawaoka H, Hori M, DuBois RN: Cyclooxygenase regulates angiogenesis induced by colon cancer. Cell 1998, 93(5):705-716.

9. Tsujii M, DuBois RN: Alterations in cellular adhesion and apoptosis in epithelial cells overexpressing prostaglandin endoperoxide synthase-2. Cell I995, 83(3):493-50I.

10. Goodwin JS, Ceuppens J: Regulation of immune response by prostaglandins. J Clin Immunol 1983, 3(4):295-3I 5.

II. Harris RE, Beebe-Donk J, Schuller HM: Chemoprevention of lung cancer by non-steroidal anti-inflammatory drugs among cigarette smokers. Oncol Rep 2002, 9(4):693-695.

12. Akhmedkhanov A, Toniolo P, Zeleniuch-Jacquotte A, Koenig KL, Shore RE: Aspirin and lung cancer in women. Br J Cancer 2002, 87(I):49-53.

13. Hida T, Yatabe Y, Achiwa H, Muramatsu H, Kozaki K, Nakamura S, Ogawa M, Mitsudomi T, Sugiura T, Takahashi T: Increased expression of cyclooxygenase 2 occurs frequently in human lung cancers, specifically in adenocarcinomas. Cancer Res 1998, 58( I 7):376I-3764.

14. Ermert L, Dierkes C, Ermert M: Immunohistochemical expression of cyclooxygenase isoenzymes and downstream enzymes in human lung tumors. Clin Cancer Res 2003, 9(5): $1604-1610$.

15. Spitz MR, Wei Q, Dong Q, Amos Cl, Wu Z: Genetic susceptibility to lung cancer: the role of DNA damage and repair. Cancer Epidemiol Biomark Prev 2003, I 2(8):689-698.

16. Feyler A, Voho A, Bouchardy C, Kuokkanen K, Dayer P, Hirvonen A, Benhamou S: Myeloperoxidase $-463 \mathbf{G} \rightarrow$ A polymorphism and lung cancer risk. Cancer Epidemiol Biomark Prev 2002, I I(I 2): I550- I554.

17. Papafili A, Hill MR, Brull DJ, McAnulty RJ, Marshall RP, Humphries SE, Laurent GJ: Common promoter variant in cyclooxygenase-2 represses gene expression: evidence of role in acute-phase inflammatory response. Arterioscler Thomb Vasc Biol 2002, 22(10): $1631-1636$.

18. Campa D, Zienolddiny S, Maggini V, Skaug V, Haugen A, Canzian F: Association of a common polymorphism in the cyclooxygenase 2 gene with risk of non-small cell lung cancer. Carcinogenesis 2004, 25(2):229-235.

19. Kang S, Kim YB, Kim MH, Yoon KS, Kim JW, Park NH, Song YS, Kang $D$, Yoo KY, Kang SB, Lee HP: Polymorphism in the nuclear factor kappa-B binding promoter region of cyclooxygenase- 2 is associated with an increased risk of bladder cancer. Cancer Lett 2005, 2 I 7(I): II-I6.

20. Koh WP, Yuan JM, van de Berg D, Lee HP, Yu MC: Interaction between cyclooxygenase-2 gene polymorphism and dietary $n$ 6 polyunsaturated fatty acids on colon cancer risk: the Singapore Chinese Health Study. Br J Cancer 2004, 90(9): I760-I764.

21. Cui JG, Salehi-Rad S, Rogaeva E, Lukiw WJ: Characterization of a cyclooxygenase-2 $\mathbf{- 7 6 5 G} \rightarrow C$ promoter polymorphism in human neural cells. Neuroreport 2005, I 6(6):575-579.

22. Lee SJ, Jeon HS, Jang JS, Park SH, Lee GY, Lee BH, Kim CH, Kang YM, Lee WK, Kam S, Park RW, Kim IS, Cho YL, Jung TH, Park JY: 
DNMT3B polymorphisms and risk of primary lung cancer. Carcinogenesis 2004, 26(2):403-409.

23. Lee GY, Jang JS, Lee SY, Jeon HS, Kim KM, Choi JE, Park JM, Chae MH, Lee WK, Kam S, Kim IS, Lee JT, Jung TH, Park JY: XPC polymorphisms and lung cancer risk. Int J Cancer 2005, I I 5(5):807-8I3.

24. Lee SJ, Lee SY, Jeon HS, Park SH, Jang JS, Lee GY, Son JW, Kim CH, Lee WK, Kam S, Park RW, Park TI, Kang YM, Kim IS, Jung TH, Park JY: Vascular endothelial growth factor gene polymorphisms and risk of primary lung cancer. Cancer Epidemiol Biomark Prev 2005, I 4(3):57I-575.

25. Lee CT, Kang KH, Koh Y, Chang J, Jung HS, Park SK, Yoo KY, Song JS: Characteristics of lung cancer in Korea, 1997. Lung Cancer 2000, 30(I):15-22.

26. Hu Z, Miao X, Ma H, Wang X, Tan W, Wei Q, et al:: A common polymorphism in the 3'UTR of cyclooxygenase 2 /prostaglandin synthase 2 gene and risk of lung cancer in a Chinese population. Lung Cancer 2005, 48: I I-I7.

27. Fan R, Wu MT, Miller D, Wain JC, Kelsey KT, Wiencke JK, Christiani DC: The $p 53$ codon $\mathbf{7 2}$ polymorphism and lung cancer risk. Cancer Epidemiol Biomark Prev 2000, 9(10): 1037-1042.

28. Li G, Wang LE, Chamberlain RM, Amos Cl, Spitz MR, Wei Q: p73 G4CI4-to-A4TI4 polymorphism and risk of primary lung cancer. Cancer Res 2004, 64(1 9):6836-6866.

29. Shaw $G$, Kamen $R$ : A conserved $A U$ sequence from the $3^{\prime}$ untranslated region of GM-CSF mRNA mediates selective mRNA degradation. Cell 1986, 46(5):659-667.

30. Gou Q, Liu CH, Ben-Av P, Hla T: Dissociation of basal turnover and cytokine-induced transcript stabilization of the human cyclooxygenase- 2 mRNA by mutagenesis of the 3'-untranslated region. Biochem Biophys Res Commun 1998, 242(3):508-5 I 2.

31. Dixon DA, Kaplan CD, Mclntyre TM, Zimmerman GA, Prescott SM Post-transcriptional control of cyclooxygenase-2 gene expression. J Biol Chem 2000, 275( (16): I I750-I I 757.

32. Cok SJ, Morrison AR: The 3'-untranslated region of murine cyclooxygenase-2 contains multiple regulatory elements that alter message stability and translation efficiency. J Biol Chem 200I, 276(25):23I79-23I 85.

33. Cipollone F, Toniato E, Martinotti S, Fazia M, lezzi A, Cuccurullo $C$, Pini B, Ursi S, Vitullo G, Averna M, Arca M, Montali A, Campagna F, Ucchino S, Spigonardo F, Taddei S, Virdis A, Ciabattoni G, Notarbartolo A, Cuccurullo F, Mezzetti A: A polymorphism in the cyclooxygenase 2 gene as an inherited protective factor against myocardial infarction and stroke. JAMA 2004, 29I( I 8):222I-2228.

34. Risch N]: Searching for genetic determinants in the new millennium. Nature 2000, 405(6788):847-856

35. Rebbeck TR, Ambrosone CB, Bell DA, Chanock SJ, Hayes RB, Kadlubar FF, Thomas DC: SNPs, haplotypes, and cancer: applications in molecular epidemiology. Cancer Epidemiol Biomark Prev 2004, 13(5):681-687.

\section{Pre-publication history}

The pre-publication history for this paper can be accessed here:

http://www.biomedcentral.com/1471-2407/6/70/prepub

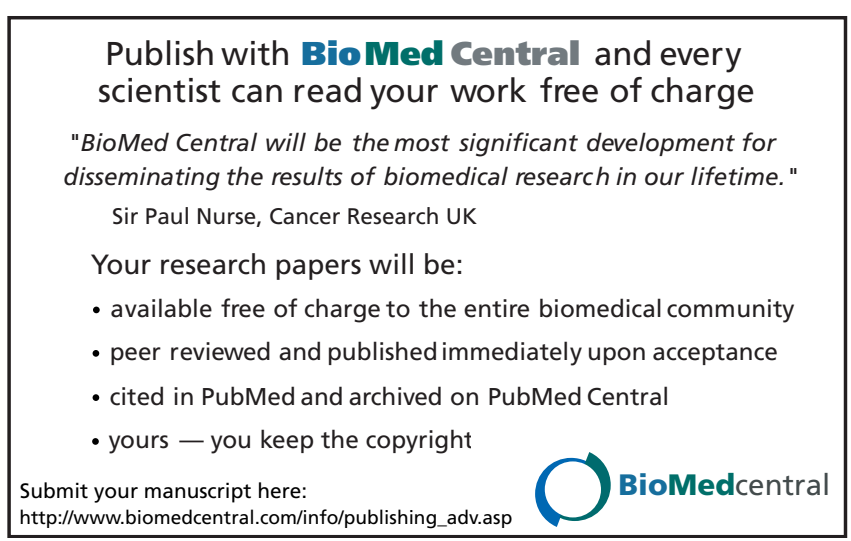

